\title{
A COMPARATIVE EVALUATION OF RADIOTHERAPY WITH CONCURRENT WEEKLY CISPLATIN VERSUS CONCURRENT WEEKLY PACLITAXEL IN PATIENTS WITH LOCALLY ADVANCED CARCINOMA CERVIX
}

\author{
Neerja Maurya1, Laxmi Singotia², A. Saxena ${ }^{3}$, S. Rawat ${ }^{4}$, T. Pounikar 5 \\ ${ }^{1}$ Senior Resident, Department of Radiotherapy, N.S.C.B. Medical College, Jabalpur. \\ ${ }^{2}$ Associate Professor \& HOD, Department of Radiotherapy, N.S.C.B. Medical College, Jabalpur. \\ ${ }^{3}$ Associate Professor, Department of Radiotherapy, N.S.C.B. Medical College, Jabalpur. \\ ${ }^{4}$ Associate Professor, Department of Radiotherapy, N.S.C.B. Medical College, Jabalpur. \\ ${ }_{5}^{5}$ Assistant Professor, Department of Radiotherapy, N.S.C.B. Medical College, Jabalpur.
}

\section{ABSTRACT}

\section{OBJECTIVES}

A prospective study to compare weekly cisplatin versus weekly paclitaxel as concurrent chemotherapy with standard radiotherapy in locally advanced carcinoma cervix.

\section{METHODS}

The study was carried out between November 2013 and August 2104; 60 newly diagnosed women with histopathologically proven squamous cell carcinoma cervix (FIGO stage IB2 to IVA were enrolled into this study and randomized to receive on weekly basis either $40 \mathrm{mg} / \mathrm{m}^{2}$ cisplatin (Control Group: 30 patients) or $50 \mathrm{mg} / \mathrm{m}^{2}$ paclitaxel (Study Group: 30 patients) concurrently with radiotherapy total dose for radiotherapy 80 Gy for both the groups (50 Gy from EBRT and 30 Gy from HDR brachytherapy). Followup time was 6 months.

\section{RESULTS}

The mean number of chemotherapy cycles was comparable with $86.7 \%$ and $80 \%$ of patients receiving 5 doses in control and study group respectively. At the completion of treatment 20 patients (66.7\%) in control group and 15 patients (50\%) in study group had complete response; 10 patients (33.3\%) in control group and 15 patients (50\%) in study group had partial response. After 6 months of followup, 23 patients (76.7\%) in control group and $19(63.3 \%)$ patients of study group had complete response and $7(23.4 \%)$ patients of control group and 10 (33.4\%) patients of study group had partial response respectively. One patient of study group developed progressive disease during followup period.

\section{CONCLUSION}

This small prospective study shows that weekly paclitaxel does not provide any clinical advantage over weekly cisplatin for concurrent chemoradiation for locally advanced carcinoma cervix and associated with more gastrointestinal and haematological toxicities.

\section{KEYWORDS}

Chemotherapy, Radiotherapy, Toxicity, Response.

HOW TO CITE THIS ARTICLE: Maurya N, Singotia L, Saxena A, et al. A comparative evaluation of radiotherapy with concurrent weekly cisplatin versus concurrent weekly paclitaxel in patients with locally advanced carcinoma cervix. J. Evolution Med. Dent. Sci. 2016;5(31):1667-1672, DOI: 10.14260/jemds/2016/393

\section{INTRODUCTION}

Worldwide, cervical cancer is both the fourth-most common cause of cancer and deaths from cancer in women.[1] In 2012, 528,000 cases of cervical cancer were estimated to have occurred with 266,000 deaths.[1] It is the second-most common cause of female-specific cancer after breast cancer, accounting for around $8 \%$ of both total cancer cases and total cancer deaths in women.[2] In developing countries, the incidence of cancer cervix is increasing and is the leading cause of cancer mortality.

Financial or Other, Competing Interest: None.

Submission 29-02-2016, Peer Review 24-03-2016,

Acceptance 30-03-2016, Published 18-04-2016.

Corresponding Author:

Dr. Neerja Maurya,

167, MIG, Dhanwantari Nagar,

Jabalpur.

E-mail: neerjamaurya2311@gmail.com

DOI: $10.14260 /$ jemds/2016/393
The disproportionately high burden of carcinoma cervix in developing countries is largely due to lack of screening that allows detection of precancerous and early stage carcinoma cervix, so most of the cases present at advanced stages (FIGO stage III/IV).

Radiation therapy is a clinical modality dealing with the use of ionizing radiations in the treatment of patients with malignant neoplasm (And occasionally benign diseases). The aim of radiation therapy is to deliver a precisely measured dose of irradiation to a defined tumour volume with as minimal damage as possible to surrounding healthy tissue, resulting in eradication of the tumour, a high quality of life and prolongation of survival at competitive cost.[3]

Patients with carcinoma cervix usually present with locally advanced disease (FIGO stage IIB, III and IV) in which surgery has higher morbidity. Radiotherapy plays a major role in management of these patients. 
The limitation of radiotherapy in controlling pelvic diseases for locally advanced carcinoma cervix is that radiation doses required to treat large tumours in the setting of poor tumour oxygenation exceeds the limit of toxicity in normal tissue. This was the main reason for treatment failure supporting by the fact that about $70 \%$ of relapses have pelvic failure as the first sites.[4,5] Many strategies have been made trying to improve outcomes in locally advanced diseases such as uses of hypoxic cell sensitizers, hyperbaric oxygen, neutron therapy and hyperfractionation. However, results of those mentioned were found limited or unsuccessful.[6]

In 1999, five large prospective randomized trials performed by the Gynaecologic Oncology Group (GOG), Radiation Therapy Oncology Group (RTOG) and the SouthWest Oncology Group (SWOG) demonstrated significant survival advantage and superiority in reducing risk of death by $30-50 \%$ in cisplatin-based therapy given concurrently with pelvic radiotherapy when compared to either radiotherapy alone or radiotherapy in concurrent with nonplatinum containing chemotherapy.[7-11] It was stated that cisplatin-based chemoradiotherapy also decreased the relative risk of recurrence and the mortality. Based on the results of these five randomized clinical trials, which consistently showed improved survival in patients treated with cisplatin-based concurrent chemoradiotherapy the National Cancer Institute (NCI) of the United States announced that "Strong consideration should be given to the incorporation of concurrent cisplatin-based chemotherapy with RT in women who require radiation therapy for treatment of carcinoma cervix" in 1999. Although recently reported meta-analysis studies also demonstrated improved local control rates and survival with cisplatin-based Chemotherapy Concurrent to Radiation Therapy (CCRT), the optimal cisplatin dose and dosing schedule are still undetermined. Most widely accepted concurrent chemoradiation protocol is the combination of radiation and cisplatin administered once a week at a dose of $40 \mathrm{mg} / \mathrm{m} 2$ for 6 weeks. $[12,13]$

The main side effects of cisplatin are nephrotoxicity, neurotoxicity, ototoxicity, gastrointestinal toxicity and myelosuppression. The toxicities were frequently occurred in considerable numbers of patients and many of their treatments could not be completed as scheduled. It has been known that unplanned interruptions of treatment and prolongation of treatment time have compromised the therapeutic result of radiotherapy, treatment cornerstone. A successful treatment schedule without the unplanned interruption was an important factor affecting the best result of treatment.[14,15]

In our institute, the treatment for locally advanced Carcinoma Cervix is Concurrent Chemoradiotherapy (CCRT); the protocol is cisplatin $40 \mathrm{mg} / \mathrm{m} 2$ once a week for 5 weeks in concurrent with pelvic radiation is given. Radiation is administered with Cobalt-60 teletherapy and HDR brachytherapy machine.

These facts have stimulated interests in exploring other concurrent chemotherapeutic agent with potentially more clinical effect. Paclitaxel is a taxane chemotherapy drug that was found to have significant activity in solid tumours, especially epithelial ovarian cancer, lung cancer, breast cancer and cervical cancer.[16-19] The main side effects of paclitaxel are myelosuppression, gastrointestinal toxicity, neurotoxicity and hypersensitivity reactions.

Preclinical studies have shown a radiosensitizing effect of paclitaxel in human cervical cancer cell lines.[20,21] It was also shown that this drug exerts a preferential cytotoxic activity in human cervical cancer cells with low Raf- 1 kinase activity, which makes it desirable to be used in conjunction with radiotherapy.[21] The clinical feasibility of concurrent RT and paclitaxel was tested in phase I trials and a Maximum Tolerated Dose (MTD) of $50 \mathrm{mg} / \mathrm{m} 2$ per week concurrently with radiation therapy was established. ${ }^{[22,23]}$ In addition, the clinical efficacy of paclitaxel has been tested in phase II and III studies for metastatic and recurrent cervical cancer with objective response rates ranging between 36 and 47\%.[24-26]

In this study tumour response, treatment toxicity and outcome was examined in patients with locally advanced carcinoma cervix treated by concurrent radiation therapy and chemotherapy using either weekly cisplatin or weekly paclitaxel.

\section{MATERIALS AND METHODS Study Population}

Patients presenting with locally advanced carcinoma cervix (FIGO stage IB2-IVA) will be included in this study. Patients, randomly selected and divided into two groups of 30 patients in each group. The criteria for putting a patient in a group were random and no particular patient were given a priority bias. All patients to be included in the study were histopathologically proved and registered at Govt. Cancer Hospital, NSCB Medical College, Jabalpur.

\section{Inclusion Criteria}

Histopathologically proven locally advanced squamous cell carcinoma cervix (FIGO stage IB2-IVA). Age up to 70 yrs. ECOG performance status $0-3$. Informed consent, adequate haematological and biochemical profile with absolute neutrophil count $>1.5 \times 109 / \mathrm{L}$, Platelets $>100 \times 109 / \mathrm{L}$, Creatinine $<1.5$, Liver Enzyme (AST ALT) $<3 \times$ Normal and Bilirubin $<1.25 \times$ normal

\section{Exclusion Criteria}

Patients with haematological, cardiac, renal or liver function abnormalities, hypersensitivity to Cisplatin or Paclitaxel. Distant metastasis, prior radiotherapy/chemotherapy (neoadjuvant), other synchronous malignancies.

Radiotherapy Treatment Protocol Schedule (Both Arms) Radiation treatment consists of External Beam Radiotherapy using 15MV photons and HDR brachytherapy. Cases were treated by conventional radiotherapy schedule as follows: EBRT (200 cGy/fr x 25 fr) = 50 Gy, HDR ICRT (7.5 Gy/fr x 3 fr) $=30$ Gy (equal to LDR), Total Dose $=80$ Gy. EBRT was given 5 days a week with total duration of 25 days and after completion of EBRT 3 fraction of weekly ICRT was given. Total duration of completion of treatment with EBRT and ICRT should be 56 days. Portals for EBRT of pelvis: Parallel opposed (Anterior posterior fields)/four field box technique.

Concurrent Chemotherapy Protocol Schedule

Arm A (Control Group): Inj. Cisplatin 40 mg/m2 IV weekly (Ceiling dose $50 \mathrm{mg}$ ). 
In this group randomly selected previously untreated patients received weekly Cisplatin $40 \mathrm{mg} / \mathrm{m} 2 \mathrm{IV}$ in $500 \mathrm{cc}$ of D5-NS over one hour with premedication.

Arm B (Study Group): Inj. Paclitaxel $50 \mathrm{mg} / \mathrm{m} 2$ IV weekly (Ceiling dose $70 \mathrm{mg}$ ). In this group, randomly selected previously untreated patients received weekly Paclitaxel 50 $\mathrm{mg} / \mathrm{m} 2 \mathrm{IV}$ in $500 \mathrm{cc}$ of NS in a glass bottle over 1 hour by using IV set with codon filter.

Premedication consists of Dexamethasone $8 \mathrm{mg}$ IV, Pheniramine IV, Ranitidine $50 \mathrm{mg}$ IV and a 5HT3-receptor antagonist as antiemetic.

\section{Pretreatment Evaluation}

Complete history and general physical examination with an assessment of the patient's performance. Quality of life assessments must be done prior to the start of any protocol treatment.

\section{Lab Studies}

Complete Blood Count, Blood Sugar, Renal Function Test, Blood Sugar, Renal Function Test, Liver Function Test, Imaging studies - Chest X-ray (PA view), USG Abdomen and Pelvis, CT/MRI Abdomen and Pelvis (when required).

\section{Observation During Radiotherapy}

Patients (Both control and study group) receiving concurrent chemoradiation was assessed weekly for local disease response and development of any acute skin or mucosal reactions. Grading of normal tissue reactions was done by RTOG (Radiation therapy oncology group) and WHO common toxicity criteria (Appendix IV). Doses at which patients develop acute skin/mucosal reaction was noted for both control and study group. Any bladder/bowel symptom at specific dose was noted. Haematological and renal function test was evaluated weekly during treatment.

\section{Evaluation after Completion of Treatment and Followup}

Patients were evaluated at the end of treatment and 1st, 3rd and 6th month followup visits by PS/PV and local examination. Haematological investigations, Chest X-ray and USG abdomen and pelvis will also be done on followup visits. Response was evaluated in terms of Stable Disease (SD), Partial Response (PR), Progressive Disease (PD) or Complete Response (CR).

\section{OBSERVATION}

At the end of treatment, 15 patients (50\%) of study group with $95 \%$ confidence interval 31.3 to $68.7 \%$ and 20 patients (66.7\%) of control group with $95 \%$ confidence interval 47.2 to $82.7 \%$ had complete response $(\mathrm{P}=0.190) ; 15$ patients (50\%) of study group with $95 \%$ confidence interval 31.3 to $68.7 \%$ and 10 patients (33.4\%) of control group with $95 \%$ confidence interval 17.3 to $52.8 \%$ had partial response $(\mathrm{P}=0.190)$.

At the $1^{\text {st }}$ month of followup, 17 patients (56.7\%) of study group with $95 \%$ confidence interval 37.4 to $74.5 \%$ and 21 patients $(70 \%)$ of control group with $95 \%$ confidence interval 50.6 to $85.3 \%$ had complete response $(\mathrm{P}=0.28)$, whereas 12 patients (43.4\%) of study group with $95 \%$ confidence interval 22.7 to $59.4 \%$ and 9 patients (30\%) of control group with $95 \%$ confidence interval 14.7 to $49.4 \%$ had partial response
$(\mathrm{P}=0.42) ; 1$ patient (3.3\%) had progressive diseases in study group.

At $3^{\text {rd }}$ to $6^{\text {th }}$ month of followup, 19 patients $(63.3 \%)$ of study group with $95 \%$ confidence interval 43.9 to $80.5 \%$ and 23 patients $(76.7 \%)$ of control group with $95 \%$ confidence interval 57.7 to $90.1 \%$ had complete response $(\mathrm{P}=0.26)$, whereas 10 patients (33.4\%) of study group with 95\% confidence interval 17.3 to $52.8 \%$ and 7 patients $(23.4 \%)$ of control group with $95 \%$ confidence interval 9.9 to $42.3 \%$ had partial response $(\mathrm{P}=0.39)$; 1 patient $(3.3 \%)$ had progressive diseases in study group. However, this difference was not found statistically significant. During followup period, none of the patients in study and control group develop metastasis.

\section{DISCUSSION}

The aim of this prospective study was to evaluate toxicity, compliance and response of weekly paclitaxel with concurrent radiotherapy versus weekly cisplatin concurrent with radiotherapy in the treatment of locally advanced squamous cell carcinoma of cervix. The present study was carried out on 60 histopathologically confirmed newly diagnosed cases of squamous cell carcinoma cervix Stage IB2 to IVA; 60 consecutive patients met the eligibility criteria and were enrolled; 30 patients were randomized to the cisplatin arm (Group 1) and 30 patients to the paclitaxel arm. In this study, patients were mostly from rural background in their $5^{\text {th }}$ and $6^{\text {th }}$ decade of life having ECOG performance scale of 1 and haemoglobin level between 8-12 gm\%. The histopathological finding was moderately differentiated squamous cell carcinoma in majority of the patients under study. Age, parity, histology presence of hydronephrosis and lymph node involvement were not different in both groups. Only median tumour size was slightly larger for group II compared to group I patients, but this was not statistically significant.

Patient's Characteristics Listed in Table 1.

In this study, patients in the control group were given 5 cycles of weekly cisplatin $40 \mathrm{mg} / \mathrm{m}^{2}$ (Ceiling dose $50 \mathrm{mg}$ ) along with the radiotherapy, whereas patients in the study group were given 5 cycles of weekly paclitaxel $50 \mathrm{mg} / \mathrm{m}^{2}$ (Ceiling dose $100 \mathrm{mg}$ ) along with radiotherapy. Radiotherapy protocol was same in both groups, i.e. 50 Gy through EBRT by conventional fraction of $2 \mathrm{~Gy} / \mathrm{fr}$ through parallel opposed anterior and posterior fields along with 3 fractions of HDR brachytherapy (Each of 7.5 Gy) as soon as patient was found fit for the same. Treatment detailed are listed in Table 2. The mean number of chemotherapy cycle was compared with $87 \%$ and $80 \%$ of patients received $>4$ doses in group I and II, respectively. The median dose to point A was slightly higher for group I patients. The mean duration of radiation therapy was similar in both groups.

In this study, there was no statistically significant toxicity between the study group and control group for acute skin reaction. The statistically significant toxicity was found in control group for nausea, vomiting and nephrotoxicity, whereas in study group for haematological toxicity and diarrhoea. Treatment related acute toxicity is listed in Table 3 both groups had comparable haematological toxicity, but more patients in group II had severe allergic reaction. In group II patients, chemotherapy had to be discontinued because of drug related severe allergic reaction. Also delay in 
chemotherapy was more common with group II then with group I patients, but this difference was not statistically significant.

Our study provides a direct comparison between cisplatin and paclitaxel used as weekly concurrent chemotherapy with definitive radiation for advanced carcinoma of the cervix. Our data indicate that the overall response with the use of paclitaxel, which is the study arm are equal to those with cisplatin.

The rate of gastrointestinal (GI) toxicity in our study manifesting as severe diarrhoea and haematological toxicities as anaemia, leukopenia and neutropenia were higher in the paclitaxel arm. In addition, one patient developed neuropathy in the paclitaxel arm and chemotherapy had to be discontinued after 3 cycles. In general, more chemotherapy delays were encountered in this group. It is difficult to compare this toxicity pattern with other studies from the literature, because none of these studies used either paclitaxel or cisplatin alone for CCRT, instead they used both drugs in combination with various dose administration schedules. However, one could note that in at least 3 of the phase I studies that included paclitaxel, severe diarrhoea was the limiting toxicity which agrees with our findings.[27,28] However, because of the small size of the study it was not possible to fully evaluate the influence of these factors either separately or all combined.

The treatment response shown in Chart No. 1. The tumour response in this study was evaluated weekly during treatment and at the end of treatment. After the completion, patients were evaluated at $1^{\text {st }}, 3^{\text {rd }}$ and $6^{\text {th }}$ month followup visits. Reduction in the tumour size was seen comparatively more in the control group and rendering them fit for brachytherapy earlier than the study group. In the $5^{\text {th }}$ week of treatment, $26.6 \%$ in the study group and $36.6 \%$ in the control group had complete response and in the $6^{\text {th }}$ week, $40 \%$ in the study group and $56.6 \%$ in the control group had complete response.

At end of the completion of treatment, $50 \%$ in the study group and $66.7 \%$ in the control group were found to have complete response to the treatment; $50 \%$ and $33.4 \%$ were found to have partial response in the study and control group respectively. After 6 months of completing the treatment the result in both the groups, $63.3 \%$ in the study group and $76.7 \%$ in the control group were found to have complete response to the treatment; $33.4 \%$ and $23.4 \%$ were found to have partial response in the study and control group respectively. One patient in study group develops progressive disease after one month of followup. There is no metastasis found in any patient of both group during followup, Table No. 4.

Though the difference in tumour response was not statistically significant, the rate of reduction in tumour size was found faster in control group at the end of the treatment.

The response to treatment in the present study was found to be better in patients in their $5^{\text {th }}$ or $6^{\text {th }}$ decade of their life as compared to those in their $7^{\text {th }}$ decade of life because of better physical activity and less associated comorbid conditions, those with urban background as compared to rural background, ECOG performance status 1 at presentation as compared to those with ECOG performance status 2 because of better general condition in the former group.
The response to treatment was also found to be better in patients with haemoglobin more than $10 \mathrm{gm} \%$ as compared to those with haemoglobin less than $10 \mathrm{gm} \%$ at presentation because of favourable effect on sense of wellbeing and energy level in the former group.

The response to treatment was also found to be better in patients with well/moderately differentiated histopathology as compared to poorly differentiated histopathology of primary tumour as it is more responsive to radiotherapy and in those patients with better compliance to treatment.

All the above factors were not to be observed as per the plan of this thesis, but need a mention at this place to show that no one factor can be the only cause of better or bad results of a particular regimen.

The results in present study with 6 months followup were quite encouraging, but the post-treatment followup was too short to definitely establish the role of this regimen. It needs further evaluation.

In summary, these data show that concurrent chemoradiation for advanced cervical cancer using weekly paclitaxel was not superior to concurrent cisplatin and was associated with more severe gastrointestinal and haematological toxicities but less nausea, vomiting and nephrotoxicity.

\section{CONCLUSION}

A prospective clinical study provides a direct comparison between cisplatin and paclitaxel used as weekly concurrent chemotherapy with definitive radiation for locally advanced carcinoma cervix. The aim of present study was to evaluate toxicity, efficacy and response of two different weekly-based chemotherapy concurrent with radiotherapy.

The response of treatment in both the groups was assessed by WHO criteria. At the completion of treatment, $50 \%$ patients of study group and $66.7 \%$ of control group had complete response, whereas $50 \%$ of study and $33.4 \%$ of control group had partial response. On followup visits, $63.3 \%$ patients of study group and $76.7 \%$ of control group had complete response, whereas $10 \%$ of study group and $7 \%$ of control group had partial response. One patient on control group developed progressive disease after one month of followup. The response in control group was slightly better than study group that was statistically not significant.

Haematological toxicities and acute diarrhoea were seen more in study group than control group, however, was managed comfortably. Compliance was slightly more in the study group, the average time in the study group to complete radiotherapy was 59 days and control group had 60 days as average time.

It is hereby concluded that concurrent chemoradiation for locally advanced carcinoma cervix using weekly paclitaxel was not superior to concurrent cisplatin and was associated with more severe gastrointestinal and haematological toxicities but less nausea, vomiting and nephrotoxicity.

However, the results were encouraging and it shall require larger number of patients and longer followup in order to arrive at a concrete conclusion as far as disease free survival, cause specific survival, pelvic control rate and longterm sequelae or complications are concerned. 


\begin{tabular}{|c|c|c|}
\hline & Study Group & Control Group \\
\hline No. of Patients & 30 & 30 \\
\hline Median age (Years) & 45.97 & 48.47 \\
\hline $\begin{array}{c}\text { Squamous cell } \\
\text { pathology }\end{array}$ & 28 & 29 \\
\hline Stage (IIB-IIIA) & 19 & 15 \\
\hline $\begin{array}{c}\text { Median tumour size } \\
\text { (cm) }\end{array}$ & $4.75(2.5-7)$ & $4.25(3-5.5)$ \\
\hline $\begin{array}{c}\text { Haemoglobin } \\
\text { (Mean) gm\% }\end{array}$ & 10.69 & 11.15 \\
\hline $\begin{array}{c}\text { Blood urea (Mean) } \\
\text { mg/dL }\end{array}$ & 25.18 & 23.90 \\
\hline $\begin{array}{c}\text { Serum creatinine } \\
\text { (Mean) mg/dL }\end{array}$ & 0.89 & 0.95 \\
\hline $\begin{array}{c}\text { Table 1: Patient's Characteristics. Study Group Received } \\
\text { Concurrent Paclitaxel and Control Group Received } \\
\text { Concurrent Cisplatin }\end{array}$ \\
\hline \multicolumn{3}{|c|}{} \\
\hline
\end{tabular}

\begin{tabular}{|c|c|c|}
\hline & $\begin{array}{c}\text { I (STUDY } \\
\text { GROUP) }\end{array}$ & $\begin{array}{c}\text { II (CONTROL } \\
\text { GROUP) }\end{array}$ \\
\hline Chemo Cycles & 5 cycles & 5 cycles \\
\hline $\begin{array}{c}\text { Weekly dose of } \\
\text { chemo drug }\end{array}$ & $\begin{array}{c}50 \mathrm{mg} / \mathrm{m}^{2} \\
\text { paclitaxel }\end{array}$ & $40 \mathrm{mg} / \mathrm{m}^{2}$ cisplatin \\
\hline$>4$ cycles & $\begin{array}{c}24 \text { patients } \\
(80 \%)\end{array}$ & 26 patients (86.7\%) \\
\hline EBRT dose & $\begin{array}{c}50 \mathrm{GY} @ 200 \text { Cgy } \\
\text { per fraction }\end{array}$ & $\begin{array}{c}50 \mathrm{GY} @ 200 \mathrm{Cgy} \\
\text { per fraction }\end{array}$ \\
\hline HDR ICRT dose & $\begin{array}{c}30 \text { gy@7 Gy in } \\
\text { 3\#at point A }\end{array}$ & $\begin{array}{c}30 \mathrm{GY} 27 \text { Gy in3\#AT } \\
\text { point A }\end{array}$ \\
\hline \multicolumn{2}{|c|}{ Table 2: Chemotherapy and Radiotherapy } \\
Treatment Parameters
\end{tabular}

\begin{tabular}{|c|c|c|c|}
\hline Toxicity & $\begin{array}{c}\text { Study } \\
\text { Group }\end{array}$ & $\begin{array}{c}\text { Control } \\
\text { Group }\end{array}$ & $\begin{array}{c}\text { Significance } \\
\text { (p value) }\end{array}$ \\
\hline $\begin{array}{c}\text { Acute skin } \\
\text { reaction }\end{array}$ & $27(90 \%)$ & $\begin{array}{c}26 \\
(86.6 \%)\end{array}$ & - \\
\hline Nausea & $5(16.6 \%)$ & $\begin{array}{c}30 \\
(100 \%)\end{array}$ & $\begin{array}{c}0.001 \\
\text { (grade II) }\end{array}$ \\
\hline Vomiting & $7(23.4 \%)$ & $\begin{array}{c}28 \\
(93.33 \%)\end{array}$ & $\begin{array}{c}0.002 \\
\text { (grade I) }\end{array}$ \\
\hline Diarrhoea & $\begin{array}{c}17 \\
(56.66 \%)\end{array}$ & $\begin{array}{c}13 \\
(43.3 \%)\end{array}$ & $\begin{array}{c}0.0003 \\
\text { (grade II) }\end{array}$ \\
\hline Anaemia & $30(100 \%)$ & $\begin{array}{c}28 \\
(93.33 \%)\end{array}$ & $\begin{array}{c}0.001 \\
\text { (grade III) }\end{array}$ \\
\hline Leucopenia & $\begin{array}{c}28 \\
(93.33 \%)\end{array}$ & $\begin{array}{c}12 \\
(40 \%)\end{array}$ & - \\
\hline Neutropenia & $\begin{array}{c}19 \\
(63.33 \%)\end{array}$ & $9(30 \%)$ & - \\
\hline Nephrotoxicity & $\begin{array}{c}5 \\
(16.66 \%)\end{array}$ & $\begin{array}{c}11 \\
(36.66 \%)\end{array}$ \\
\hline \multicolumn{2}{|c|}{ Table 3: Incidence and Types of Acute Toxicity } \\
\hline
\end{tabular}

\begin{tabular}{|c|c|c|c|c|}
\hline & \multicolumn{2}{|c|}{ Complete Response } & \multicolumn{2}{|c|}{ Partial Response } \\
\hline & $\begin{array}{l}\text { Study } \\
\text { Group }\end{array}$ & $\begin{array}{l}\text { Control } \\
\text { Group }\end{array}$ & $\begin{array}{l}\text { Study } \\
\text { Group }\end{array}$ & $\begin{array}{l}\text { Control } \\
\text { Group }\end{array}$ \\
\hline $1^{\text {st }}$ week & 0 & 0 & 0 & 0 \\
\hline $2^{\text {nd }}$ week & 0 & 0 & $\begin{array}{c}1 \\
(3.3 \%)\end{array}$ & $\begin{array}{c}4 \\
(13.3 \%)\end{array}$ \\
\hline $3^{\text {rd }}$ week & 0 & 0 & $\begin{array}{c}22 \\
(73.3 \%) \\
\end{array}$ & $\begin{array}{c}27 \\
(90.0 \%) \\
\end{array}$ \\
\hline $4^{\text {th }}$ week & $\begin{array}{c}3 \\
(10 \%) \\
\end{array}$ & $\begin{array}{c}5 \\
(16.3 \%) \\
\end{array}$ & $\begin{array}{c}27 \\
(90 \%) \\
\end{array}$ & $\begin{array}{c}25 \\
(83.3 \%) \\
\end{array}$ \\
\hline $5^{\text {th }}$ week & $\begin{array}{c}8 \\
(26.6 \%) \\
\end{array}$ & $\begin{array}{c}11 \\
(36.6 \%) \\
\end{array}$ & $\begin{array}{c}22 \\
(73.3 \%) \\
\end{array}$ & $\begin{array}{c}19 \\
(63.3 \%) \\
\end{array}$ \\
\hline $6^{\text {th }}$ week & $\begin{array}{c}12 \\
(40 \%) \\
\end{array}$ & $\begin{array}{c}17 \\
(56.6 \%) \\
\end{array}$ & $\begin{array}{c}18 \\
(60 \%)\end{array}$ & $\begin{array}{c}13 \\
(43.4 \% \\
\end{array}$ \\
\hline End of & 15 & 20 & 15 & 10 \\
\hline
\end{tabular}

\begin{tabular}{|c|c|c|c|c|}
\hline treatment & $(50 \%)$ & $(66.7 \%)$ & $(50 \%)$ & $(33.4 \%)$ \\
\hline \multirow{2}{*}{$1^{\text {st }}$ month } & $\begin{array}{c}17 \\
(56.7 \%)\end{array}$ & $\begin{array}{c}21 \\
(70 \%)\end{array}$ & $\begin{array}{c}12 \\
(43.4 \%)\end{array}$ & $\begin{array}{c}9 \\
(30 \%)\end{array}$ \\
\hline \multirow{2}{*}{$3^{\text {rd }}$ month } & $\begin{array}{c}19 \\
(63.3 \%)\end{array}$ & $\begin{array}{c}23 \\
(76.7 \%)\end{array}$ & $\begin{array}{c}10 \\
(33.4 \%)\end{array}$ & $\begin{array}{c}7 \\
(23.4 \%)\end{array}$ \\
\hline \multirow{2}{*}{$6^{\text {th }}$ month } & 19 & 23 & 10 & 7 \\
& $(63.3 \%)$ & $(76.7 \%)$ & $(33.4 \%)$ & $(23.4 \%)$ \\
\hline \multicolumn{5}{|c|}{ Table 4: Treatment Response } \\
\hline
\end{tabular}

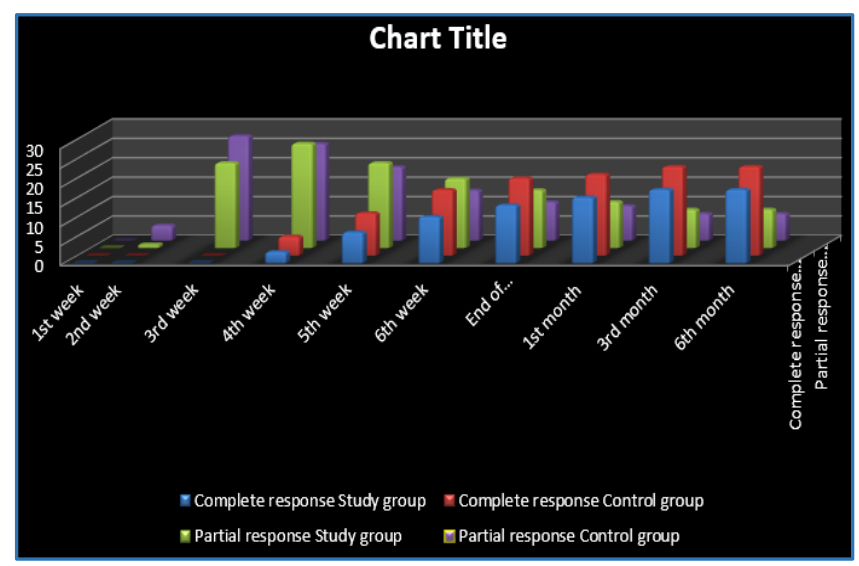

Chart 1

\section{ACKNOWLEDGEMENT}

The author would like to thank all the participants and their relatives in the study for their cooperation.

\section{REFERENCES}

1. World Cancer Report 2014. World Health Organization. Chapter 5.12. ISBN 9283204298, 2014.

2. World Cancer Report 2014. World Health Organization. Chapter 1.1. ISBN 9283204298, 2014.

3. Einhorn N, Trope C, Ridderheim M, et al. A systematic overview of radiation therapy effects in cervical cancer (cervix uteri). Acta Oncol 2003;42(5-6):546-56. doi: $10.1080 / 02841860310014660$.

4. Eifel PJ, Morris M, Wharton JT, et al. The influence of tumor size and morphology on the outcome of patients with FIGO stage IB squamous cell carcinoma of the uterine cervix. Int $\mathrm{J}$ Radiat Oncol Biol Phys 1994;29(1):9-16.

5. Fyles AW, Pintilie M, Kirkbride $P$, et al. Prognostic factors in patients with cervix cancer treated by radiation therapy: results of a multiple regression analysis. Radiother Oncol 1995;35(2):107-17. doi: 10.1016/0167-8140(95)01535-0.

6. Logsdon MD, Eifel PJ. FIGO IIIB squamous cell carcinoma of the cervix: an analysis of prognostic factors emphasizing the balance between external beam and intracavitary radiation therapy. Int J Radiat Oncol Biol Phys 1999;43(4):763-75.

7. Keys HM, Bundy BN, Stehman FB, et al. Cisplatin, radiation and adjuvant hysterectomy compared with radiation and adjuvant hysterectomy for bulky stage IB cervical carcinoma. N Engl J Med 1999;340:1154-61. doi: 10.1056/NEJM199904153401503.

8. Morris M, Eifel PJ, Lu J, et al. Pelvic radiation with concurrent chemotherapy compared with pelvic and para-aortic radiation for high-risk cervical cancer. $\mathrm{N}$ Engl J Med 1999;340:1137-43. doi: 10.1056/NEJM199904153401501. 
9. Kumar JV, Doval DC, Rao R, et al. A retrospective study of patients with locally advanced cancer of the cervix treated with neoadjuvant chemotherapy followed by radical surgery. Int J Gynecol Cancer 2009;19(3):41722.

10. Park DC, Suh MJ, Yeo SG. Neoadjuvant paclitaxel and cisplatin in uterine cervical cancer: long-term results. Int J Gynecol Cancer 2009;19(5):943-7.

11. Umayahara K, Takeshima N, Nose $\mathrm{T}$, et al. Phase I study of concurrent chemoradiotherapy with weekly cisplatin and paclitaxel chemotherapy for locally advanced cervical carcinoma in Japanese women. Int J Gynecol Cancer 2009;19(4):723-7.

12. Tewari KS, Monk BJ. Recent achievements and future developments in advanced and recurrent cervical cancer: trials of the gynecologic oncology group. Semin Oncol 2009;36(2):170-180. doi: 10.1053/j. seminoncol. 2008.12.008.

13. Walker JL, Morrison A, DiSilvestro P, et al. Gynecologic oncology group. A phase I/II study of extended field radiation therapy with concomitant paclitaxel and cisplatin chemotherapy in patients with cervical carcinoma metastatic to the para-aortic lymph nodes: a gynecologic oncology group study. Gynecol Oncol 2009;112(1):78-84. doi: 10.1016/j. ygyno. 2008. 09.035.

14. Rose PG, Bundy BN, Watkins EB, et al. Concurrent cisplatin-based radiotherapy and chemotherapy for locally advanced cervical cancer. $N$ Engl J Med 1999;340(15):1144-53. doi: 10.1056/NEJM199904153401502.

15. Wong LC, Ngan HYS, Cheung ANY, et al. Chemoradiation and adjuvant chemotherapy in cervical cancer. J Clin Oncol 1999;17(7):2055-60.

16. Peters WA, Liu PY, Barrett RJ, et al. Concurrent chemotherapy and pelvic radiation therapy compared with pelvic radiation therapy alone as adjuvant therapy after radical surgery in high-risk early-stage cancer of the cervix. J Clin Oncol 2000;18(8):1606-13.

17. Whitney CW, Sause W, Bundy BN, et al. Randomized comparison of fluorouracil plus cisplatin versus hydroxyurea as an adjunct to radiation therapy in stage IIB-IVA carcinoma of th`2e cervix with negative paraaortic lymph nodes: a gynecologic oncology group and southwest oncology group study. J Clin Oncol 1999;17(5):1339-48.
18. National Cancer Institute. Concurrent chemotherapy for cervical cancer. Clinical announcement, Washington, DC. 1999.

19. McNeil C. New standard of care for cervical cancer sets stage for next questions. J Natl Cancer Inst 1999;91(6):500a-501a.

20. Eifel PJ. Concurrent chemotherapy and radiation therapy as the standard of care for cervical cancer. Nat Clin Pract Oncol 2006;3(5):248-55.

doi: $10.1038 /$ ncponc0 486 .

21. Thomas GM. Improved treatment for cervical cancerconcurrent chemotherapy and radiotherapy. N Engl J Med 1999;340(15):1198-200. doi: 10.1056/ NEJM199904153401509.

22. Thomas GM. Concurrent chemotherapy and radiation for locally advanced cervical cancer: the new standard of care. Semin Radiat Oncol 2000;10(1):44-50. doi: 10.1016/S1053-4296(00)80020-X.

23. Rose PG. Concurrent chemoradiation for locally advanced carcinoma of the cervix: where are we in 2006? Ann Oncol 2006;17(10):x224-x229. doi: 10.1093/annonc/mdl264.

24. Eifel PJ, Winter K, Morris M, et al. Pelvic irradiation with concurrent chemotherapy versus pelvic and para-aortic irradiation for high-risk cervical cancer: an update of radiation therapy oncology group trial (RTOG) 90-01. J Clin Oncol 2004;22(5):872-80. doi: 10.1200/JC0.2004.07.197.

25. Pearcey R, Brundage M, Drouin P, et al. Phase III trial comparing radical radiotherapy with and without cisplatin chemotherapy in patients with advanced squamous cell cancer of the cervix. J Clin Oncol 2002;20(4):966-72. doi: 10.1200/JC0.20.4.966.

26. McGuire WP, Hoskins WJ, Brady MF, et al. Cyclophosphamide and cisplatin compared with paclitaxel and cisplatin in patients with stage III and stage IV ovarian cancer. N Engl J Med 1996;334(1):1-6. doi: 10.1056/NEJM199601043340101.

27. Kudelka AP, Winn R, Edwards CL, et al. Activity of paclitaxel in advanced or recurrent squamous cell cancer of the cervix. Clin Cancer Res 1996;2(8):1285-8.

28. NCCN (National Comprehensive Cancer Network) guidelines, version 1.2012, Inc. 2010. 